\title{
Sustentabilidade como vantagem competitiva nas organizações: um levantamento da responsabilidade das empresas
}

O estudo tem por objetivo descrever a responsabilidade social empresarial e a sustentabilidade organizacional como dois caminhos estratégicos possíveis à serem adotados pelas organizações em prol de ofertarem a busca pelo alcance das metas de vantagens competitivas sustentáveis previstas e dos objetivos traçados pelas empresas responsáveis ecologicamente correta. Metodologicamente, se caracteriza como uma pesquisa básica, conceitual, explicativa, qualitativa, discursiva e bibliográfica. A vantagem competitividade sustentável impulsiona as organizações a refletir constantemente sobre como maximização dos resultados operacionais em busca de uma diferenciação estratégica. Empresas com estratégias sustentáveis têm grandes negócios no ambiente empresarial, podendo abrir novos segmentos de mercado e revolucionar os que já existem desde que invistam nas competências necessárias, não medindo esforços para construir uma sociedade mais justa, começando pelo nível mais alto empresarial, governamental, chegando até no âmbito social.

Palavras-chave: Responsabilidade Social; Desenvolvimento Sustentável; Ecoeficiência.

\section{Sustainability as a competitive advantage in organizations: a survey of corporate responsibility}

\begin{abstract}
The study aims to describe the corporate social responsibility and organizational sustainability as two possible strategic paths to be adopted by the organizations in order to offer the search for achieving the goals of sustainable competitive advantages provided for and objectives outlined by the companies responsible ecofriendly. Methodologically, is characterized as a basic research, conceptual, explanatory, qualitative, and discursive essay. The sustainable competitive advantage drives organizations to reflect constantly about how maximization of operational results in search of a strategic differentiation. Companies with sustainable strategies have great deals in the business environment, and may open new market segments and revolutionize the that already exist since to invest in skills, not measuring efforts to build a fairer society, starting at the highest level, Government business, even in the social area.
\end{abstract}

Keywords: Social Responsibility; Sustainable Development; Ecoefficiency.

Topic: Gestão Ambiental e da Biodiversidade

Reviewed anonymously in the process of blind peer.
Received: 11/01/2019

Approved: 21/04/2019
Grenda Tabarana de Oliveira

Faculdade Maurício de Nassau, Brasil

http://lattes.cnpq.br/4506310764720067

grendatabarana@hotmail.com

Rosinei Melo da Silva

Faculdade Maurício de Nassau, Brasil

http://lattes.cnpq.br/2886444236145412

neidejesus40@gmail.com

Alysson Pereira Cardoso

Faculdade Maurício de Nassau, Brasil

http://lattes.cnpq.br/0625403733471827

alysson.888@hotmail.com

\author{
Marivaldo Souza Oliveira \\ Universidade Federal do Rio Grande do Norte, Brasil \\ msoliveira@gmail.com \\ Rosecelia Moreira Castro (it \\ Universidade Federal Rural da Amazônia, Brasil \\ http://lattes.cnpq.br/2265654785335940 \\ http://orcid.org/0000-0001-8382-8636 \\ rmsilva@museu-goeldi.br \\ Alvaro José de Almeida Pinto \\ Universidade da Amazônia, Brasil \\ http://lattes.cnpq.br/9982946507934692 \\ alvarojalmeidapinto@yahoo.com.br
}

Referencing this:

OLIVEIRA, G. T.; SILVA, R. M.; CARDOSO, A. P.; OLIVEIRA, M. S.; CASTRO, R. M.; PINTO, A. J. A.. Sustentabilidade como vantagem competitiva nas organizações: um levantamento da responsabilidade das empresas. Revista Brasileira de Administração Científica, v.9, n.1, p.127-136, 2018. DOI: http://doi.org/10.6008/CBPC2179684X.2018.001.0009 


\section{INTRODUÇÃO}

O crescimento de crimes ambientais nas organizações vem sendo alvo de mudanças no sistema natural de nossa sociedade a cada ano, pelo fato de raramente serem punidos e a falta de consciência na tomada de decisão das organizações. Em 1962, a publicação nos Estados Unidos, do livro Primavera Silenciosa, (Silent Spring, em inglês) da bióloga Rachel Carson, denunciou pela primeira vez ao público leigo a insidiosa contaminação do meio ambiente por resíduos tóxicos decorrentes do uso de pesticidas químicos.

No final dos anos 60, um grupo formado por cientistas, intelectuais e empresários, denominado Clube de Roma (DONELLA et al., 1972), discutia a tese da incompatibilidade entre o modelo de desenvolvimento vigente e o meio ambiente. Sob esse enfoque, o planeta rumaria para a catástrofe se os países subdesenvolvidos passassem a adotar níveis de consumo dos recursos naturais semelhantes aos dos países desenvolvidos. Como resultado desses estudos, em 1971, foi publicado o relatório dos cientistas Dennis e Donella Meadows, denominado Limites do Crescimento, no qual previam que a continuação de um crescimento exponencial da economia mundial abalaria os fundamentos naturais da vida.

O conceito de sustentabilidade começou a ser delineado na Conferência das Nações Unidas sobre o Meio Ambiente Humano, realizada na Suécia, na cidade de Estocolmo em 1972, a primeira conferência da Organização das Nações Unidas sobre o meio ambiente e a primeira grande reunião internacional para discutir as atividades humanas em relação ao meio ambiente (AGUIAR, 1994).

O relatório Brundtland (1987) é o documento intitulado Nosso Futuro Comum 'Our Common Future', publicado em 1987, neste documento o desenvolvimento sustentável são concebidos como o desenvolvimento que satisfaz as necessidades presentes, sem comprometer a capacidade das gerações futuras de suprir suas próprias necessidades, o relatório de Brundtland abriu um imenso debate da academia sobre o significado de desenvolvimento sustentável.

Silva (2009) explica que o interesse por sustentabilidade se originou durante a década de 1980, a partir da conscientização dos países em descobrir formas de promover o crescimento sem destruir o meio ambiente, nem sacrificar o bem-estar das futuras gerações. Já Rosa (2007), afirma que a sustentabilidade pode ser considerada um conceito importado da ecologia, mas cuja operacionalidade ainda precisa ser provada nas sociedades humanas. Em uma sociedade sustentável, o progresso é medido pela qualidade de vida (saúde, longevidade, maturidade psicológica, educação, ambiente limpo, espírito comunitário e lazer criativo) ao invés de puro consumo material (FERREIRA, 2005).

A ECO-92 Conferência sobre Meio Ambiente e Desenvolvimento realizada em 1992 (BOTELHO, 2012), no Rio de Janeiro, consolidou o conceito de desenvolvimento sustentável. A mais importante conquista da Conferência foi colocar esses dois termos, meio ambiente e desenvolvimento, juntos concretizando a possibilidade apenas esboçada na Conferência de Estocolmo, em 1972, e consagrando o uso do conceito de desenvolvimento sustentável, defendido, em 1987, pela Comissão Mundial sobre Meio Ambiente e Desenvolvimento. Para Martins (2002), as Conferências das Nações Unidas e os seus documentos finais respectivos sempre refletem o equilíbrio de forças internacionais no momento em que foram realizadas. 
O coordenador geral dos preparativos da Conferência Rio+20, na Rio-92 Luiz Alberto Figueiredo Machado, chegou à conclusão de que se tem de agregar os componentes econômicos, ambientais e sociais, mas se isso não for feito, não há como se garantir a sustentabilidade do desenvolvimento (BOTELHO, 2012). Dessa maneira, a sustentabilidade como fator de contribuição dos administradores, oferecem um olhar mais amplo sobre o diferencial que as empresas assumem por respeitarem o meio ambiente.

A partir de então, várias outras conferências e acordos internacionais têm sido organizados de modo a promover o caráter de urgência na implementação do modelo de sustentabilidade em escala mundial. As empresas, os governos e a sociedade civil organizada, como principais fatores desse processo, devem atuar conjuntamente de modo a encontrar o ponto de equilíbrio entre as dimensões econômica, social e ambiental em todas as suas iniciativas e atividades de modo a garantir o bem-estar da sociedade e o futuro do próprio planeta (LEAL, 2013).

A necessidade da sustentabilidade passou a ser um alvo de preocupação nas empresas devido aos grandes processos de transformações no século XXI, como mudanças tecnológicas, econômicas, políticas, culturais e principalmente sociais que ocorrem na sociedade, assim também como a ética e a moral que também passam por certas mudanças até mesmo de valores.

O termo sustentabilidade significa atender as necessidades atuais sem comprometer a capacidade de atender as necessidades das gerações futuras. A sustentabilidade empresarial pode ser interpretada como a integração dos desempenhos econômicos, sociais e ecológicos (VELLANI, 2011). O desenvolvimento sustentável pode influenciar direta e indiretamente no comportamento das empresas, pois, em todo o mundo, elas estão se deparando com problemas não somente econômicos, mas também sociais e ambientais (ALMEIDA, 2002), assegura que, a sustentabilidade no âmbito organizacional consiste em três dimensões inter-relacionadas: a econômica, a social e a ambiental.

Este trabalho foi desenvolvido para retratar como as práticas sustentáveis podem proporcionar redução de custos, oferecem rentabilidade e vantagem competitiva as organizações, assim trazendo a questão em foco: De que forma a sustentabilidade pode gerar vantagem competitiva para as organizações?. A organização é favorecida adotando as práticas de desenvolvimento sustentável, como maior satisfação dos clientes, melhoria da imagem da empresa, conquista de melhores mercados, qualidade de vida, melhoria do desempenho do colaborador na empresa, entre outros, na qual, percebe-se que, os recursos naturais passaram a ficar cada vez mais escassos e acabam agredindo cada vez mais o meio ambiente, logo prejudicando o fator econômico, social e ambiental.

A busca por vantagem competitiva é uma prioridade para as empresas que operam em ambiente global e complexo, de forma a garantir a capacidade de gerar valor e longo-prazo (ELKINGTON, 1994). Da mesma forma, é crescente a preocupação da sociedade com a necessidade empresarial de se buscar equilíbrio sustentável entre desenvolvimento econômico, meio ambiente e social. Nessa percepção, a gestão sustentável deve ser vista não separadamente do desenvolvimento econômico, mas sim, como um grande modelo de gestão que traz, em um futuro próximo, a vantagem competitiva de ser ecologicamente melhor 
(DONAIRE, 1999). Portanto, a empresa que desenvolve uma boa gestão sustentável, possui um diferencial no mercado e procura alcançar suas metas com responsabilidades sociais.

Cria-se uma ideologia de que as políticas de responsabilidade socioambiental devam se basear nas particularidades do negócio, de clientes e investidores e sejam desenvolvidas conforme a cultura organizacional. Dessa forma, ao inserir práticas sustentáveis nas empresas, é necessário observar a cultura existente, bem como seus costumes e práticas, para que seja possível adequar as ações aos critérios já existentes, de forma a facilitar a compreensão e engajamento dos indivíduos.

Sendo assim, empresas que adotam ações socioambientais são mais competitivas e, nesse contexto, é imperativo compreender que o sucesso de uma organização está intimamente relacionado à sua cultura, por meio da construção de relacionamentos com os meios interno e externo (MELETI, 2012). As empresas que implantam ações socioambientais precisam conhecer o ambiente como um todo para ter um crescimento organizacional dinâmico e eficiente.

De acordo com Barbiere (2010), incentivar a inovação da gestão na sustentabilidade organizacional está diretamente relacionado com a competitividade futura do negócio, sendo necessário, por parte da organização, um acompanhamento por meio dos indicadores sustentáveis, compondo essa nova prática organizacional. Assim, a sustentabilidade, como vantagem competitiva, também influencia no fator relevante para a gestão empresarial obter um bom desempenho no processo administrativo.

Para Lima (2007), as práticas organizacionais socialmente responsáveis e o respeito ao meio ambiente por parte da organização dão credibilidade à gestão do negócio que é muito valorizado por grandes empresas e a sociedade, contribuindo assim, para sua permanência e seu crescimento no mercado, diminuindo o risco da mortalidade, como também, tendem a ter uma gestão mais consciente. Vale dizer que quando uma organização tem um comprometimento de gestão ambiental com à sociedade, logo a economia em sua volta prevalece com mais harmonia em seus negócios.

Na gestão administrativa, as práticas de sustentabilidades são muito comuns atualmente, com considerável aumento da parcela da população que se preocupa com o meio ambiente. 0 aumento dessa preocupação traz à tona um novo grupo de consumidores, e é este grupo que as empresas visam atingir, porém, por ser um tema altamente amplo e muito discutido, o conceito e a ideia de sustentabilidade vêm atingindo todos os tipos de público, o que é benéfico para a sociedade e organização que vem adotando essa prática no meio ambiente em que vive.

\section{DISCUSSÃO TEÓRICA}

Leal (2013), diz que as empresas, os governos e a sociedade civil organizada, como fundamentais atores desse processo, devem agir conjuntamente de modo a encontrar o ponto de equilíbrio entre as 3 dimensões econômica, social e ambiental em todas as suas iniciativas e atividades de modo a garantir o bemestar da sociedade e o futuro do próprio planeta, contribuindo para a sustentabilidade. Portanto, a sustentabilidade de uma empresa dependerá, basicamente, de sua capacidade de estabelecer um equilíbrio sustentável para a sua competitividade no mercado. 
De acordo com Tachizawa (2009), o quanto antes as organizações começarem a observar o meio ambiente como seu principal desafio e como oportunidade competitiva, maior será a chance que sobrevivam. Também afirma que, em qualquer segmento da economia, a gestão ambiental é considerada importante ferramenta para capacitação de condições de competitividade para as empresas. Desta forma, as organizações tornam-se mais competitivas, pois ao reduzir custos estão aptas a praticar melhores preços, além de adquirem novos clientes pelas manifestações socialmente responsáveis.

Conceitua Dias (2009), a otimização do uso de recursos naturais e energia e a redução de resíduos e emissões ao meio ambiente são estratégias de prevenção que geram benefícios para a empresa, como a redução de custos de produção e um melhor posicionamento frente ao mercado, além de melhorar a qualidade do produto por meio de processos eficientes, com isso, obtêm um desenvolvimento em seu setor, ganha credibilidade e confiança dos seus consumidores.

Maximiano (2007), entende que a gestão se refere a uma ação eficaz de tomar decisões sobre a utilização de recursos, para possibilitar a realização de objetivos e compreende os processos de Planejamento, Organização, Liderança, Execução e Controle. Visto que processo de planejamento administrativo é de extrema importância para o direcionamento das atividades operacionais da empresa sustentável.

Para Lozano (2011), esses instrumentos de gestão viabilizam aos gestores alcançarem suas metas, sejam elas: aumentar lucros, reduzir custos, melhoria de qualidade, inovar, ou se planejar para o futuro com o objetivo de alcançar vantagens competitivas, mais, sobretudo, estabelecer as melhores soluções adequadas para a tomada de decisão. Com isso estabelecer diretrizes administrativas que atendam de maneira precisa e eficaz na realização de projetos sustentáveis que ofereçam oportunidades e melhorias no processo de gestão da organização.

Como caracteriza Coltro (2011), as empresas passaram a adotar instrumentos de gestão direcionadas ao planejamento de suas atividades para promover o alcance de suas metas, igualmente os modelos de gestão foram se adaptando às novas situações e às necessidades das organizações. Nas últimas décadas as empresas passaram à pró-agir, adotando estratégias de gestão ambiental, em busca de maiores avanços no mercado. Com o intuito que tem como foco, a busca pelo alcance das metas de vantagens competitivas sustentáveis previstas e dos objetivos traçados pelas empresas responsáveis ecologicamente correta.

Para se ter uma experiência bem-sucedida de desenvolvimento sustentável, é necessário que exista um ambiente político e social favorável, expresso em um plano de governo consistente, baseado em um planejamento bem elaborado, onde sejam priorizadas orientações básicas para tal intento. Sendo que seu objetivo final é a busca de um equilíbrio econômico, social e ambiental contínuo, que está relacionada a sustentabilidade ambiental no mercado.

Segundo Fujihara (2003), ao criar uma cadeia de valor sustentável, ou seja, que dê igual prioridade aos objetivos econômicos, ambientais e sociais, a empresa consegue reduzir custos e riscos, aumentar a qualidade, portanto, a sustentabilidade organizacional, não é estável, mas sim continuamente dinâmica, competitiva, parcial, relevante, eficiente e eficaz, quando planejada de forma correta e segura. 
Gomes (2013) afirma que é necessário que haja propostas e processos bem definidos para a neutralização de impactos ambientais nas organizações e que todas as áreas e departamentos da organização, no geral, estejam engajados e participem de forma efetiva, conduzidos pelos respectivos gestores, de modo que deverão sempre ter consciência da maneira como conduzirão os negócios, revendo suas crenças e valores. Sendo que a sustentabilidade se apresenta como um fator condicional, relevante e indispensável para as empresas no mundo atual.

De acordo com Fraga et al. (2010), a perspectiva financeira é a parte em que a sustentabilidade é abordada com mais ênfase nos projetos da organização, onde deverá induzir uma mudança organizacional, integrando todas as ações das outras perspectivas para manutenção da sustentabilidade. Uma vez que, a empresa ambiental é aquela que contribui para o desenvolvimento sustentável e que implica no seu desempenho econômico, organizacional, cultural, social e administrativo.

Frickmann (2007) confirma que crescimento econômico e qualidade ambiental podem andar juntas e trazer lucros para a organização, por conta do ganho de eficiência e de mercado, mas para isto é preciso mudança de comportamento. Assim, pode apresentar medidas econômicas para alcançar o desenvolvimento sustentável e ao mesmo tempo aumentar a lucratividade de seus negócios.

Exemplifica Ansoff et al. (2009) que a estratégia é uma ferramenta potencialmente poderosa para lidar com as condições de mudança que cercam a empresa atualmente e segundo a missão e a visão da empresa precisam ser traduzidas em objetivos e medidas que reflitam os interesses e as expectativas dos seus principais stakeholders, para que assim, sejam desenvolvidas alianças estratégicas que permitem a criação de ações mais eficientes e de melhor desempenho (HERRERO, 2005). Dessa forma, as organizações têm um papel relevante no sentido de contribuir para o consenso cultural e social, através de uma prática empresarial sustentável.

As Práticas Sustentáveis têm grande importância no cotidiano, e pode ser altamente lucrativa nas empresas, aumentando a competitividade entre as mesmas e contribuindo com a saúde da humanidade. As empresas possuem fatores incorporados de alta relevância, sendo a, a sustentabilidade e a responsabilidade socioambiental. Sendo assim despertar o interesse em conhecer como as empresas preocupam-se com as ações das suas atividades sustentáveis é extremamente relevante.

Contudo, compreende-se que a gestão ambiental nas organizações é de suma importância nesse processo de sustentabilidade, para desenvolver estratégias viáveis e que garanta o retorno social, ambiental, econômico e vantagem competitiva zelando pelos recursos naturais e pela preservação da vida em todos os aspectos. Fazer gestão ambiental é um compromisso com o planeta e uma responsabilidade para com toda a sociedade.

\section{Vantagem competitiva}

Silva (2009), destaca que a busca das empresas por vantagem competitiva tem sido uma constante em relação às questões ambientais e suas implicações, para um planeta que não dispõe de capacidade 
suficiente de absorção de poluição. Com isso, a procura por vantagem competitiva nas organizações está sendo prioridade como papel contínuo de destaque no mercado.

A competitividade organizacional apresenta dependência direta da capacidade da organização em criar e explorar inovações que impulsionam os resultados organizacionais por meio da vantagem competitiva e melhor produtividade (SANTOS, 2011). Portanto, as organizações que possuem um bom gerenciamento conseguem criar e explorar inovações ambientais para obterem resultados e minimizar custos.

A gestão da empresa é resolver se é uma restrição ou uma oportunidade, nessa perspectiva, as organizações necessitam de estratégias para agirem mediante o mercado altamente competitivo (MORIN, 2007). Dessa forma, o planejamento estratégico é fundamental para estabelecer metas e obter melhorias continua na sua organização.

Por meio de uma gestão estratégica bem estruturada, a organização pode encontrar uma vantagem competitiva sustentável, uma vez que, se todas as áreas estiverem em sinergia e seu papel seja desempenhado de acordo com o planejamento, os concorrentes enfrentarão maiores dificuldades para identificar e imitar a mesma estratégia (BARNEY, 2007). Com a interligação de todos os departamentos as organizações possuem um desempenho eficiente e eficaz, para assim, facilitar o desenvolvimento sustentável nas empresas.

\section{Desenvolvimento sustentável}

O conceito de Desenvolvimento Sustentável é relativamente recente e surgiu inicialmente com o nome de Eco Desenvolvimento, no início da Revolução, em um contexto de controvérsias sobre as relações entre crescimento econômico e meio ambiente, centrado, sobretudo, pela publicação do relatório do Clube de Roma, que pregava o crescimento zero como forma de evitar a catástrofe ambiental (MAY, 2010). De fato, a ética e a moral, tem um papel fundamental quando existem relações entre o desenvolvimento econômico e o meio ambiente.

O termo Desenvolvimento Sustentável significa atender às necessidades da geração atual e futura. A gestão ambiental é uma alternativa para corrigir os erros cometidos pelo capitalismo, promovendo o crescimento e a conservação ambiental principalmente nas empresas. Como explica Valle (2002) foi apenas na segunda metade do século XX que um grupo de cientistas, reunidos no chamado Clube de Roma, na década de 1960, utilizando-se de modelos matemáticos, preveniu dos riscos de um crescimento econômico contínuo baseado na exploração de recursos naturais esgotáveis. Em decorrência da situação sustentável ser um desafio para grandes e médias empresas, todos nós estamos envolvidos nesse mesmo foco.

Vizeu et al. (2012) propõem uma reflexão sobre o conceito de desenvolvimento sustentável e mencionam que a sustentabilidade se torna cada vez mais importante na medida em que a destruição econômica e da natureza se intensificam. Desenvolvimento Organizacional é uma forma de implantar um modelo de mudança planejada, assim como o que existe sobre estudos do comportamento dos indivíduos nas organizações, que possam minimizar os impactos causados pelas mudanças. Desenvolvimento 
Sustentável Organizacional, tem como pressuposto básico que toda mudança dentro das empresas, seja de natureza pública ou privada, deve ocorrer de forma planejada e ordenada.

\section{Ecoeficiência}

A ecoeficiência baseia-se na ideia de que a redução de materiais e energia por unidade de produto ou serviço aumenta a competitividade da empresa, ao mesmo tempo em que reduz as pressões sobre o meio ambiente, seja como fonte de recurso, seja como depósito de resíduos (BARBIERI, 2007). Por isso, a empresa que implanta fontes alternativas, também possui vantagem competitiva como sustentabilidade na organização.

Segundo Salgado (2004), a inserção de práticas ecoeficientes direciona a organização para uma grande vantagem competitiva diante de seus concorrentes, e para que isso ocorra existem três preceitos fundamentais que devem ser aplicados: (1) redução do consumo de recursos naturais, tais como energia, matérias, água e solo; (2) redução no impacto na natureza, a qual se entende pela diminuição na poluição do ar e da água; e (3) aumento da produtividade ou no valor do produto/serviço. De fato, essas práticas ecoeficientes levam a empresa a aumentar a receita.

A ideia do ecoeficiência é inerente às discussões de sustentabilidade organizacional (SAVITZ, 2007). Quando a organização busca por métodos de redução dos impactos negativos gerados por suas atividades e de utilização mais responsável dos recursos produtivos consumidos por ela, admite-se que existe um interesse de conquistar um estágio maior de eficiência, no caso, de ecoeficiência (BLEISCHWITZ, 2003). Em outras palavras, mantendo equilíbrio sustentável dos recursos naturais, diminuem os impactos negativos ambientais causados pelas organizações.

Nesse mesmo segmento, Piotto (2003) discorre sobre a ecoeficiência como o saber combinar desempenho econômico e ambiental, reduzindo ao mesmo tempo os impactos ambientais; utilizando mais racionalmente matérias-primas e energia; reduzindo riscos de acidentes e melhorando a relação da organização com as partes interessadas (stakeholders). De fato, as empresas precisam agregar o termo eco eficiência a seus colaboradores da redução de impactos econômicos e ambientais.

As competências em foco agregam um valor diferenciado para os clientes das organizações e são articuladas por evoluções exigidas pelas ações estratégicas das organizações, em conformidade com o produto e o mercado em que elas atuam (MILLS et al., 2002; FLEURY et al., 2008). Portanto, em um ambiente envolvido por ações estratégicas, as competências representam os conceitos que explicam o teor competitivo das organizações.

Sendo assim, em um contexto organizacional, a ecoeficiência depende de um mecanismo de gestão que concede a ela a capacidade de ser avaliada, mensurada e, principalmente, aprimorada (KAPTEIN et al., 2002). Resumindo, os gestores necessitam utilizar suas ferramentas de aprimoramento para desenvolver suas atividades sustentáveis. 


\section{CONCLUSÕES}

A vantagem competitiva sustentável impulsiona as organizações a refletir constantemente sobre como maximização dos resultados operacionais em busca de uma diferenciação estratégica. Dessa forma, a organização deve consolidar um diferencial competitivo sustentável através do uso de novas práticas e tecnologias sustentáveis. Empresas fazem mais diferença para o planeta e a sociedade quando inserem a sustentabilidade no meio de sua estratégia de negócios.

Porém a organização deve inovar em suas rotinas, práticas e produtos, pois os desafios socioambientais são atitudes decisivas na busca pela sustentabilidade, sendo vistos como oportunidade de vantagem competitiva. Empresas com estratégias sustentáveis têm grandes negócios no ambiente empresarial, podendo abrir novos segmentos de mercado e revolucionar os que já existem desde que invistam nas competências necessárias, não medindo esforços para construir uma sociedade mais justa, começando pelo nível mais alto empresarial, governamental, alcançando até no âmbito social.

\section{REFERÊNCIAS}

AGUIAR, R. A. R.. Direito do meio ambiente e participação popular. Brasília: IBAMA, 1994.

ALMEIDA, F.. O bom negócio da sustentabilidade. Rio de Janeiro: Nova Fronteira, 2002.

ANSOFF, H. I.; MCDONNELL, E. J.. Implantando a administração estratégica. São Paulo: Atlas, 2009.

BARNEY, J.; HESTERLY, W. S.. Administração estratégica e vantagem competitiva. São Paulo: Pearson Prentice Hall, 2007.

BARBIERI, J. C.. Gestão Ambiental Empresarial: Conceitos, Modelos e Instrumentos. 2 ed. São Paulo: Saraiva, 2007.

BLEISCHWITZ, R.. Cognitive and institutional perspectives of eco-efficiency. Ecological Economics, v.43, n.46, p.453-467, 2003. DOI: http://dx.doi.org/10.1016/S0921-8009(03)001861

BOTELHO, C. R. O. M.. Preservação Ambiental: um discurso de todos da Eco 92 à Rio + 20. Brasília: 1992.

BRUNDTLAND, G. H.. Nosso futuro comum. Rio de Janeiro: FVG, 1987.

COLTRO, A.. Os novos modelos de administração na era da competitividade. In: CONGRESSO VIRTUAL BRASILEIRO DE ADMINISTRAÇÃO, 8. Anais. São Paulo, 2011.

DIAS, R.. Gestão ambiental: responsabilidade social e sustentabilidade. 5 ed. São Paulo: Atlas, 2009.

DIAS, M. A. P.. Administração de Materiais: princípios, conceitos e gestão. 5 ed. São Paulo: Atlas, 2009.

DONAIRE, D.. Gestão ambiental na empresa. 2 ed. São Paulo: Atlas, 1999.
DONELLA, H. M.; DENNIS, L. M.; RANDERS, J.; BEHRENS, W. W.. Os Limites do Crescimento. 2 ed. São Paulo: Pespectiva, 1971.

ELKINGTON, J. T.. The sustainable corporations: win-win-win businesses estrategies for sustainable development. Sacramento: Academy Management Review, 1994.

FERREIRA, L. C.. Sustentabilidade uma abordagem histórica da sustentabilidade. In: BRASIL. Encontros e Caminhos: Formação de Educadores Ambientais e Coletivos Educadores. Brasília: MMA, 2005.

FLEURY, A.; FLEURY, M. T. L.. Estratégias empresariais e formação de competências: um quebra-cabeça caleidoscópico da indústria brasileira. 3 ed. São Paulo: Atlas, 2008.

FRAGA, R. V.; SILVA, C. E.. Balanced Scorecard: planejamento estratégico no contexto das organizações do Terceiro Setor. Revista Brasileira de Administração Científica, v.1, n.1, p.531, 2010.

FRICKMANN, C. E.. Sustentabilidade e Competitividade: O Papel das Empresas. Revista de Economia Mackenzie, v.5, n.5, p.87-101, 2007.

FUJIHARA, M. A.. Gestão da sustentabilidade do empreendimento. 2003.

GOMES, S. M. S.; LIMA, A. S.; ROCHA. L. F.; SLOMSKI, V. G. Sustentabilidade empresarial: Concepções e ações ambientais de gestores do setor alimentício. Revista Razão Contábil \& Finanças, Fortaleza, v.4, n.2, 2013.

HERRERO, F. E.. BSC e a Gestão Estratégica. Rio de Janeiro: Campus, 2005.

KAPTEIN, M.; WEMPE, J.. The balanced company: a theory of corporate integrity. Oxford: Oxford University Press, 2002. 
LEAL, C. E.. A era das organizações sustentáveis. Revista Eletrônica Novo Enfoque, v.16, n.16, p.01-12, 2013.

LIMA, A. M.. Instrumentos de Reporte de Sustentabilidade: Triple Bottom Line. Foz do Iguaçu: UFSM, 2007.

LOZANO, L.; PEREIRA, M. A. S.. Ferramentas de gestão e de apoio à tomada de decisão das unidades de agricultura familiar. Dissertação (Mestrado em Administração) Universidade Federal de Santa Catarina, Florianópolis, 2011.

MAY, P. H.; LUSTOSA, M. C.; VINHA, V.. Economia do meio ambiente: teoria e prática. 2 ed. Rio de Janeiro: Elsevier, 2010.

MARTINS, J. P. S.. A Década Desperdiçada: O Brasil, a Agenda 21 e a Rio +10. Campinas: Komedi, 2002.

MAXIMIANO, A. C. A.. Introdução à administração. 7 ed. São Paulo: Atlas, 2007

MELETI, M. V.; FADEL, B.; SMITH, M. Perspectiva sistêmica da sustentabilidade nas organizações sob a ótica da cultura organizacional e sua repercussão no desenvolvimento regional. In: CONGRESSO BRASILEIRO DE SISTEMAS. Anais. 2012.

MILLS, J.; PLATTS, K.; BOURNE, M.; RICHARDS, H.. Strategy and performance: Competing though competences. Cambridge: Cambrigdge University Press, 2002.

MORIN, E.. Educação e complexidade: os sete saberes e outros ensaios. São Paulo: Cortez, 2007.

PIOTTO, Z. C.. Eco eficiência na Indústria de Celulose e Papel: estudo de caso. Tese (Doutorado em Engenharia) Universidade de São Paulo, São Paulo, 2003.
ROSA, A.. Rede de governança ambiental na cidade de Curitiba e o papel das tecnologias de informação e comunicação. Dissertação (Mestrado em Gestão Urbana) Pontifícia Universidade Católica do Paraná, Curitiba, 2007.

SALGADO, V. G.. Proposta de indicadores de eco eficiência para o transporte de gás natural. Dissertação (Mestrado em Ciências do Planejamento Energético) - Universidade Federal do Rio de Janeiro, Rio de Janeiro, 2004.

SANTOS, J. G. C.; SILVA, L. S.; GALLON, A. V.. Os ativos intangíveis de empresas inovadoras. In: SIMPÓSIO DE ADMINISTRAÇÃO DA PRODUÇÃO, LOGÍSTICA E OPERAÇÕES INTERNACIONAIS, 14. Anais. São Paulo: SIMPOI, 2011.

SAVITZ, A. W.; WEBER, K.. A empresa sustentável: o verdadeiro sucesso é lucro com responsabilidade social e ambiental. Rio de Janeiro: Elsevier, 2007.

SILVA, D.. Sustentabilidade Corporativa. In: SIMPÓSIO DE EXCELÊNCIA EM GESTÃO E TECNOLOGIA, 6. Anais. Resende, 2009.

VALLE, C. E.. Qualidade ambiental: ISO 14000. São Paulo: São Paulo: Senac, 2002.

VELLANI, C. L.. Contabilidade e Responsabilidade. Social: Integrando Desempenho Econômico, Social e Ecológico. São Paulo: Atlas, 2011.

VIZEU, F.; MENEGHETTI, F. K.; SEIFERT, R. E.. Por uma crítica ao conceito de desenvolvimento sustentável. Caderno EBAPE.BR, v.10, n.3, p.569-583, 2012.

A CBPC - Companhia Brasileira de Produção Científica (CNPJ: 11.221.422/0001-03) detém os direitos materiais desta publicação. Os direitos referem-se à publicação do trabalho em qualquer parte do mundo, incluindo os direitos às renovaç̃os, expansões e disseminações da contribuiç̃o, bem como outros direitos subsidiários. Todos os trabalhos publicados eletronicamente poderão posteriormente ser publicados em coletâneas impressas sob coordenação da Sustenere Publishing, da Companhia Brasileira de Produção Científica e seus parceiros autorizados. Os (as) autores (as) preservam os direitos autorais, mas não têm permissão para a publicação da contribuição em outro meio, impresso ou digital, em português ou em tradução. 